Review Essay

\title{
THE LIFE IN GENDHING: CURRENT APPROACHES TO JAVANESE GAMELAN
}

\section{Michael Tenzer}

Brinner, Benjamin. Knowing Music, Making Music: Javanese Gamelan and the Theory of Musical Competence and Interaction. Chicago: University of Chicago Press, 1995. 363 pp.

Sumarsam. Gamelan: Cultural Interaction and Musical Development in Central Java. Chicago: University of Chicago Press, 1995. 350 pp.

The simultaneous recent publications of Sumarsam's Gamelan: Cultural Interaction and Musical Development in Central Java and Benjamin Brinner's Knowing Music, Making Music: Javanese Gamelan and the Theory of Musical Competence and Interaction in the prominent University of Chicago Press ethnomusicology series testifies to the sizable presence of Indonesian musicology within Western ethnomusicology. The authors' positions at Wesleyan and Berkeley respectively situate them among a disproportionately large and growing group of Indonesia specialists teaching in North American and European ethnomusicology programs. The past dozen years have seen gamelan scholarship deepening in its approach to strictly musical issues, while simultaneously broadening at the quick rate characteristic of ethnomusicology as a whole to encompass a range of concerns familiar to readers with a social-science orientation: regionalism, identity, media, popular culture, and so on. These two publications come at the crest of a recent wave of books and dissertations that extend an already lengthy bibliography. ${ }^{1}$

${ }^{1}$ For a bibliography of Javanese gamelan see Heins, E., Bibliography of Javanese Gamelan 1923-1990 (Basel: Amadeus Verlag, 1990). Recent books include two by R. A. Sutton: Traditions of Gamelan Music in Java 
Though linked by their common concern with Javanese gamelan, these new works are radically different from one another. Sumarsam addresses himself to the Javanist community by offering a new history of Javanese music in which its contexts and influences are depicted as fundamentally syncretic, while Brinner uses gamelan as the linchpin for a collection of cross-cultural observations on how musicians everywhere learn to play and play together. The ensuing critique explores the merits and weaknesses of the authors' approaches and seeks to contextualize their work in relation to the growing body of thought about Javanese gamelan, doing so from my own slightly distanced perspective of being a Balinist and a composer. The expertise I lack to argue a particular point of Javanese cultural or musical detail will hopefully turn out to be a strength for this particular task, as it leaves me in a one-foot-in position, able to gauge musical matters with some degree of acuity but all the same keen to extract points of more general relevance. Before addressing the authors' work directly, however, I will survey current issues in gamelan musicology, extracting some key points useful for framing the subsequent discussion.

\section{Issues in Gamelan Scholarship}

When timely and momentous concerns in fieldwork and research narrative appear to be assuming a status of universal importance among those in the professions, we may recall that such theoretical crises have their genesis in local situations: that is, they emerge from the specifics of the encounter between the researcher and the object of study, thus varying from place to place and depending on the scholar's interests and the nature of the research. This is prosaic to be sure, but I mention it to point out that issues like representational authenticity and the insider/outsider dichotomy (to name but two) that have ascended through the social science family tree from its anthropological roots to its ethnomusicological branch are reflected with less than full force in Javanese music scholarship.

Numerous reasons can be cited for this. As Sumarsam documents extensively (it is one of the central points of his book), when Western researchers study gamelan today they encounter a stream of discourse originally fostered by colonial-era interactions between court musicians, the Dutch, and mestizo intellectuals. From the beginning the refinements of court culture and the circumscribed domains of Yogyanese and Solonese musical influence were far from alienating to foreigners, who in general responded positively to gamelan. Since Jaap Kunst's Toonkunst von Java widened the stream into a river, it has remained for the scholars of the past several decades to simply build their vessels and set sail. As a result discourse about gamelan has not suffered that much from conflicts over whose voice is most authoritative or whose perspective is bona fide. Indeed, once Becker and Feinstein's translations of gamelan writings by Javanese authors appeared, it was clearer than ever to Western researchers

Cambridge: Cambridge University Press, 1991), and Variation in Javanese Gamelan Music: Dynamics of a Steady State (DeKalb: Northern Ilinois University Center for Southeast Asian Studies, 1993), the latter based on his 1982 dissertation. Another is Neil Sorrell, A Guide to the Gamelan (Portland: Amadeus Press, 1990), which is aimed at a general readership. New dissertations include (among others) Rene Lysloff, Shrikandhi Dances Lengger: A Performance of Music and Shadow Theater in Banyumas (West Central Java) (University of Michigan, 1990), and Marc Perlman, Unplayed Melodies: Music Theory in Postcolonial Java (Wesleyan University, 1994). 
that there was no shortage of provocative disagreement among Javanese themselves about musical matters. ${ }^{2}$

In Java, the Dutch-nurtured elites' agreed-upon conceptualization of gamelan as a Western-style high-art culture (adi luhung) facilitated an aesthetic approach to the music's appreciation and engendered a parallel scholarly interest in attending predominantly to matters of musical structure. Foreign researchers absorbed this perspective, and as a result the paradigm for discussing Javanese music continued until quite recently to be much more musicological than anthropological. This was a purely local resolution of an ideological debate preoccupying ethnomusicologists that for the past few decades has tipped the scale in the other direction elsewhere in the world. Consider, for example, diachronic changes in researchers' views of music in sub-Saharan Africa. Pre- and early colonial discourse about African music was dismissive, describing it as cacophonous and primitive. This attitude was transformed in the work of sympathetic late colonial scholars like Hornbostel and A. M. Jones, who found the music almost impenetrably difficult and complex, and has changed yet again in much recent writing, where extensive contextualization is deemed prerequisite for meaningful musical understanding. The link among these points of view is the perceived extreme "otherness" of Africa and African music (more extreme than Java's), an enduring trope that continues to fuel controversy over who is qualified to represent Africa, whether the music itself can bear the weight of discussion without anthropological framing, whether there are sufficient indigenous terms or metaphors for musical structure (so-called ethnotheory) to construct a viable emic discourse of music, and so on. ${ }^{3}$

Most recent gamelan writings by Westerners have flowed from the keypads of younger scholars who initially encountered the music during or soon after the wave of expansion of non-Western performance in music departments and conservatories during the 1970s. Written theories of gamelan emanating from the performing arts academies in central Java were also on the increase before and during this period, for reasons further detailed by Perlman. ${ }^{4}$ Though small, the number of Javanese musicians engaged in scholarship of a type roughly comparable to Western-style is sufficient to qualify the entire enterprise as collaborative, and all the more so since the publication of Becker and Feinstein's volumes. To use a word Sumarsam likes, the polyvocal exchange among gamelan scholars has been "fruitful". Clearly in the case of Java we have something unusual for ethnomusicology: an evolving print discourse in which multiple authors from multiple cultures, over a period of years and through their many contributions to an expanding corpus, are engaged in mutual illumination, provocative disagreement, and inquiry that have already begun to exert measurable

\footnotetext{
2 Judit Becker and Alan Feinstein, eds., Source Readings in Javanese Gamelan and Vocal Music, 3 Vols. (Ann Arbor: The University of Michigan Center for South and Southeast Asian Studies, 1984, 1987, 1988).

${ }^{3}$ See V. Kofi Agawu, "Representing African Music," Critical Inquiry 18,2 (1992): 245-66.

4 Perlman, Unplayed Melodies, pp. 60-90.
} 
impact on the music culture they seek to explain. ${ }^{5}$ This sort of cross-cultural interaction enriches ethnomusicology; in other world areas the lack of local scholarly participation may compel researchers to adopt dialogic strategies to compensate. Also unlike work done on Java, many studies (here again Africa is a good site for comparison) still aim to stake out new and unclaimed ethnographic and methodological territory, and therefore may end up without corroboration or challenge.

I see two aspects of the situation that are worth problematizing, however: the degree of accessibility of gamelan scholars' research to other ethnomusicologists and social scientists, and the related issue of how wide a spectrum their discourse ought to encompass along the continuum of technical-to-metamusical (or anthropologicallybased) thought. In terms of Western ethnomusicology as a whole, the extraordinary level of detail in some gamelan discourse, particularly the long-dominant stream of it concerned with the intrinsically musical matters of pathet (mode), garap (performance realization) balungan (skeletal melody) and so forth, has isolated Javanists, making them seem less in tune with the discipline and creating a situation in which outsiders find it increasingly difficult to enter into their ongoing conversations. From their own perspective the high music theory content of their dialogue is a crucial, not to mention irresistible, by-product of their depth of experience and expertise. Many of the best ones have been active performers for going on several decades now. None would deny, however, that the bulk of the discourse ends up being comprehensible mainly to other Javanese gamelan experts with a similar orientation. In today's climate, some would allege, the more that gamelan specialists talk shop the more their relevance is jeopardized. This has begun to change, but even at recent ethnomusicology conferences Indonesianists tend to present their papers mainly to one another at "Indonesia" sessions, and are in general less likely to be seen participating in the geographically unbound, issue-oriented panels that generate the most electricity.

Those committed to the technical end of the spectrum may ignore the problem that the institutionalized Javanese kepatihan (cipher) music notation delineates a sharp boundary between writings about Javanese gamelan and those about musics from elsewhere. Indispensable to the discourse among Javanists, it is known but barely used across the strait in Bali (not to mention other parts of the archipelago), and it acts as an impediment to other Western musicians, who moreover might conceivably be more tempted to venture into the world of gamelan were musical examples presented, perhaps with appropriate customization, in the closest thing we actually do have to a written musical Esperanto: the western clef and staff. ${ }^{6}$ To press this question, of course, is to ask Javanese to learn a new and alien system, and Western gamelan scholars to choose between speaking to their existing community and promoting their findings to a broader one. And the latter are not alone in their complacency, for, with scholars exhausted after a lengthy period of contentious debate, the issue of musical transcription has lately languished uncontested throughout ethnomusicology.

\footnotetext{
${ }^{5} \mathrm{~A}$ bibliography of recent writings on Indian or African music would be at least as long as that for Java and Bali, but in comparison those places are so much larger and more culturally multiform that the concerns of ethnomusicologists writing about them tend to overlap far less. See also J. Becker, "Southeast Asia" in Helen Myers, ed., Ethnomusicology: Historical and Regional Studies (New York: Norton, 1993), pp. 377-391 for another summary of musicological writings about Indonesia.

${ }^{6}$ See Sorrel, $A$ Guide to the Gamelan, for one such customization.
} 
Another aspect of the isolation of gamelan musicology is one that has long been systemic in ethnomusicology: the decline of cross-cultural comparative scholarship. Optimistically speaking it is not unreasonable to hope that the kind of detailed description we now have about gamelan can someday be put to use for comparative purposes. This is a potentially beneficial enterprise waiting on the back burner since the years when Western scholars began trying self-consciously to minimize their ethnocentricities and prevent the drawing of specious comparisons based on insufficient ethnographic data. We have more than "sufficient" data now, but few have been able to extend the significance of gamelan theory by seeing Javanese in relation to other world musical systems. ${ }^{7}$ This is an area where Brinner takes some promising steps, as I will discuss later. But many of the most attractive issues involved in this kind of work are music-technical ones, and in the current anthropology-centered intellectual climate most sense the unfashionableness of placing their emphasis here.

One wonders too whether it is reasonable to hope that such comparative thought could ever emanate from within Java. Javanese musicians apparently have not yet felt the need to understand gamelan prepared with more than a superficial knowledge of what other musics of the world might be able to tell them about themselves. In other words, although Javanese theories of gamelan have been formulated with plenty of input from Western scholars, gamelan music is still the sole focus of study in virtually all cases. Taking into account fiscal matters, of course, it is easy to see why there are no residencies for Japanese, Hindusthani or Nigerian musicians on Indonesian campuses (as there are on occasional Western ones), but there is clearly more to the story than this. In this regard one is at first tempted to cite the universal pretensions and acquisitive nature of Western scientific and humanistic inquiry, and perhaps to suggest that Javanese may be different, but this is an unconstructive essentialization. Brinner remarks that "Javanese musicians do not appear to be interested in enhancing their abilities through learning a completely foreign musical competence," suggesting that "musicians may fear that the diatonic Western scale will have a deleterious effect on Javanese intonation." (107) Does an answer to Wachsmann's call for "an Easterner or an African to be asked to give us an analysis of Western music in an Eastern or an African way" remain as improbable today as it felt when he made it? ${ }^{9}$ The question as to why we study ourselves and also study them, but they study themselves and not us (or other thems) deserves consideration. To posit answers to this question in terms of the "Javanese" as a society would be unfair; it is more a matter of inquiring into the social priorities of institutions that create academic agendas and thus shape the outlook of the musicians and scholars that they produce.

\footnotetext{
7 The few recent examples include Judith Becker, "A Southeast Asian Musical Process: Thai Thaw and Javanese Irama," Ethnomusicology XXIV (1980): 453- , and also Harold Powers, "Mode", in Stanley Sadie, ed., The New Grove Dictionary of Music and Musicians, 12 (London: MacMillan, 1980), pp. 376-450, which has achieved locus classicus status.

${ }^{8}$ Brinner's explanation was based on Sutton's 1991 conference paper Individuality and Writing in Javanese Gamelan Learning and a personal communication with Marc Perlman. For an interesting dialogue about Indonesian attitudes towards Western music, see the articles by Dieter Mack, Slamet Syukur, and Franki Raden grouped as "Polemik Music Indonesia," Kalam 2 (1994).

9 Klaus Wachsmann, "Applying Ethnomusicological Methods to Western Art Music," The World of Music 23, 2 (1981): 75-87.
} 
This is all in the realm of speculation. In the real world of twentieth century Java the proliferation of theory at the kraton and academic centers achieved the crucial aim of prolonging the prestige of Solonese and Yogyanese thought locally and broadening it internationally. Gradually this came to be perceived as hegemonic in its implicit denunciation of the validity of regional practices. This process was also set in motion by nationalist formulations, such as Dewantara's famous pronouncement about the pan-Indonesian importance of the peaks of regional culture. By this he primarily meant, of course, central Javanese gamelan. (Sumarsam 118) The center-periphery distinction which allowed such influence to be exercised in the early decades of independence comprises a less valuable frame of reference today, due to the periphery's gradual legitimization through government and media processes. Alongside this, an effort to correct the lopsided predisposition towards studies of court traditions has led to a recent gold rush of Western scholars diversifying away from the center and into rural areas, popular music markets, and critiques of the media and educational systems. ${ }^{10}$. Such moves can also be seen as a response to anthropologyderived imperatives calling for more pluralistic representations. In fact, these imperatives are now so influential that Brinner and Sumarsam's books, both concerned first and foremost with central Javanese gamelan, seem at first something of a throwback. In actuality they too represent a kind of diversification, albeit in yet other directions.

\section{Interpreting the Life of Gendhing}

Sumarsam's work has been valuable to the project of gamelan music theory since the 1970s. His earliest publications were motivated by a desire to respond in print to what he perceived as overly formulaic, narrow, and in some cases patently inaccurate theories of gamelan structure that had been advanced by Westerners, notably Kunst, Mantle Hood, and later Judith Becker. His most significant early contribution was the invention of the tantalizing concept of lagu batin (inner melody) -an unstated strand of melody present in musicians' inner ears as they play and guiding them to appropriate realizations of a gendhing (gamelan composition). This was both a seminal moment in the empowering of engaged Javanese musicians to speak across cultures and a reaffirmation of cultural values, for the term lagu batin has mystical connotations. I believe both cross-cultural engagement and central affirmation of values to have been served by this concept for, in addition to any previously concealed "truths" about the music that Sumarsam may have brought to light, the strength of the inner melody idea derives from its synthesis of musical epistemologies: Western-theoretical, because of the deductive analytical thought needed to tease it out of the musical information actually presented by the performers, and Javanese, both because of its prismatic subjectivity and, at the same time, because it was so clearly developed from a performing musician's best intuitive explanation of technical phenomena. Such "Javanese cultural resources for theoretical reflection and hypostatization" were probably the necessary and sufficient preconditions for the cross-cultural appeal of the inner melody concept. ${ }^{11}$

${ }^{10}$ Cases in point are Sutton, Traditions of Gamelan, and Yampolsky's recording project, Music of Indonesia Vols. 1-12 [additional volumes forthcoming], Smithsonian Folkways Recordings: 1990-97.

11 Perlman, Music Theory, p. 517. 
Sumarsam has since developed the concept through writing and teaching, expanding its range and grappling with its inconsistencies in due course. The cult of ambiguity thus spawned reflects the ascetic and subjective qualities of Javanese expression nicely, but is also compatible with both earlier Javanese and Western theory discourses and the multiple perspectives of Western postcolonial critique. For the growing number of musicians interested in analyzing gamelan compositions in terms richer than the merely formulaic ones circumscribed by earlier scholars, the questions to ask immediately became more interesting. It was no longer a matter of finding a "rational" explanation, as in Becker's rigorous theory of circular, quadripartite gong structures, 12 or Hood's conception of balungan as the sole "determinant" of pathet and the panerusan (elaborating) instruments' parts. ${ }^{13}$ "Where is the inner melody?" was the new notion to ponder, and Sumarsam's answer was, intriguingly, "It depends on which perspective you assume." The fecundity of these formulations was so attractive that they were incorporated into the discourse rapidly, and there were only attempts by other scholars to apply them, more deeply explicate them or offer related alternatives, but not to refute them. ${ }^{14}$ The reified surface sound of gendhing, already a contingent phenomenon due to the role of improvisation, now had a secret inner life as well, and a new dimension of imagination to explore.

Useful as such formulations are, they reflected a performer's, and not a critic's, perspective by addressing music theory issues to the exclusion of interpretive ones. Two decades later, Sumarsam's book testifies to his success developing the kind of thinking used to shape the inner melody concept and applying it to the problems suggested by the study of Javanese culture and history. New aspects are added to our canonical version of the Javanese musical past which, by comparison, now constitutes a fairly unidirectional and uninflected narrative. Before this book Javanese gamelan had scarce written histories, and what scholarship existed was imagined from an essentially diffusionist point of view. Kunst, wishing to reconstruct gamelan's beginnings, portrayed the Hindu-Buddhist and Islamic past from a thoroughly courtcentered perspective, while Hood, continuing on his mentor's course, extrapolated the remote origins of bronze technology in Java by combining archeological evidence with speculation about the decisive impact of trade and warfare with Chinese mercantile powers. ${ }^{15}$ In contrast Sumarsam uses inner melody's self-same frame of contingency to write a richer narrative, showing it to be one of the variety of influences that we would in fact expect. In this account, court culture is always heterogeneous and even the distant past culturally diverse. Most of the intercultural influences cited are not manifest in sound at the surface of the music but rather in the many ways it has been constructed, represented, transmitted, performed, and used; in short Sumarsam depicts the rich "atmosphere of musical life." (13) The absorption of foreign influences in music is seen, in turn, as "an allegory of the dynamics of Java's social and cultural

12 Judith Becker, Traditional Music in Modern Java (University of Hawaii Press: Honolulu, 1980), pp. 105146.

${ }^{13}$ M. Hood, The Nuclear Theme as a Determinant of Pathet in Javanese Music (1954; Reprinted New York: Da Capo, 1977).

14 They were applied in Sorrel, Guide to the Gamelan and explicated in Perlman, Music Theory. Suhardi's alternative, also discussed by Perlman, is presented in R. A. Sutton, "Concept and Treatment in Javanese Gamelan Music, with Reference to the Gambang," Asian Music 11 (1) (1979): 59-79.

${ }^{15}$ See M. Hood, The Evolution of Javanese Gamelan, Book I, (Wilhelmshaven: Noetzel, 1984). 
history." (2) What is striking is how interpretive play is foregrounded, and how actual musical sound becomes a by-product of deeper and more pervasive processes, much as it does in the world of inner melody.

Sumarsam's historical coverage (Chapters 1-3) begins with Majapahit and extends to the present. Even under Majapahit, given short shrift due to its more extensive treatment in Kunst and Hood, issues of pluralism and cultural interaction are stressed. In Chapter 1 ("The Early History of Javanese Music") we read of the diversity of ensembles maintained at court, the dissemination of Hindu literature through all levels of society, and ongoing Javanese interaction with Bali, which, Sumarsam aptly notes, did not mean that the latter rushed to relinquish its own cultural identity. The ensuing centuries of Islamic assimilation, also somewhat cursorily discussed owing to the paucity of available sources, are encapsulated as a period of tolerance, accommodation and adjustment. Sufi mysticism, described as compatible with earlier Hindu attitudes (25) is shown to have had a great impact on the refinement and development of wayang and gamelan in the eighteenth and nineteenth centuries, even as its celebratory aspects contributed to the popularity of the bacchanalian tayuban entertainments.

Chapter 2 ("European Colonialism, Islam, and the Peranakan Chinese") depicts the preservation-minded mestizo and totok (un-Javanized Dutch) interacting at court in the nineteenth century and actively importing European culture. The Javanese response to this is described in terms of a process of secularization in court ritual, which encompassed a lessening of the role of Islamic expressive forms, and a corresponding re-Hinduization of the arts and literature. This discussion is unfortunately benign, for Sumarsam is preoccupied with the changes manifest in the expressive forms and their contexts only, and not in any implications that Dutch policy or strategy may have abetted such changes. Were totok officials merely the providers of Western models and attitudes to be adapted at court, or can they be said to have had political ends in mind similar to those used later in Bali? Robinson chronicles cynical Dutch efforts to strengthen the court and caste system in twentieth century Bali as a way to reify the hierarchical nature of the state, thus solidifying an order with themselves at the top. ${ }^{16}$ This strengthened Balinese notions of their Majapahit past and created a framework for delineating a "traditional" Bali. In both cases, certainly, the outside presence catalyzed a sharper, more conservative cultural self-image.

In one of the most adventuresome passages, Sumarsam portrays the entwinement of eroticism, performing arts, and political power at court, relying heavily on the Serat Centhini. But his descriptions of public sexuality at court in Java are again rather benign, for he seems mainly interested in determining whether they are "fact or fiction." (38) Following the author as he notes that "Sufism had become part of the aristocrats' world view," (36) that "there was an intimate linkage between religious activity and secular emotion," (40) and that Sufi terbangan (frame drum ensemble) music helped to "provoke this [erotic] behavior," one wishes also for a more probing interpretation. Can one look behind the putative eyewitness accounts in the Centhini and attempt to discover how and whether this sexuality is encoded in the materials of the expressive forms themselves? Perhaps this would have been too wide a digression,

${ }^{16}$ G. Robinson, The Dark Side of Paradise: Political Violence in Bali (Ithaca: Cornell University Press, 1995), pp. 19-51. 
but it is instructive nonetheless to compare Sumarsam's approach with what Vickers did for Bali by interpreting the discourse of power and sexuality in Malat literature, painting, and performance genres. He sees these as legitimatizing strategies for Balinese royalty during the same period. Vickers is able, for example, to support the notion that in the Malat,

the emotional discourse which emerges is one in which the world of the text is primarily a world of desire and sensuality which may be expressed in love, anger and other feelings. The purpose of this emotionalism is perceived to be a kind of psychological control, but control with a political message. Its effects are not only attributed to the Malat, but to the forms in which it is found, and to texts which are similar. ${ }^{17}$

I would argue further that in Balinese gamelan, sexuality-and related topoi of danger, magic and witchcraft-can be read in musical structure. The discourse of courtly desire Vickers sees in the Malat-based gambuh theater is transformed and enriched in the many musical genres that developed from it. The repertoire for the gambuh ensemble of flutes, rebab and percussion was transferred nearly verbatim for the bronze gamelan semar pegulingan, which played outside the royal bedchamber and had an explicitly erotic function. Semar pegulingan blended more with village theater and acquired connotations of magic when it developed into the gamelan pelegongan in the nineteenth century; this ensemble performed music both for the gambuh-derived legong dances and the combative tales of sexuality and sorcery such as calonarang, which involved numerous magical elements important in village life. The bamboo gamelan gandrung, a slightly later development in the same musical lineage that once was associated with dances of prostitution, 18 uses pelegongan-type melodic structures to underpin an often wild and asymmetrical kind of melodic ornamentation that seems directly to reflect its associations of public sexuality. If one compares music composition and structure in gambuh/semar pegulingan with pelegongan and gandrung, one also finds gong cycles, ornamentation patterns and melodic shapes that point to specific tropes expressive of the kinds of stylized emotion Vickers portrays. In contemporary kebyar gamelan all of these elements plus others combine, so that an intertextual reading of structural components can begin to help us construct more historically informed interpretations of the music. I wonder how Javanese gamelan of the past two hundred years would submit to a comparable approach. Indeed, such efforts have had major impact on historical study of Western music in recent years; why should they not do the same for gamelan? I see this kind of reading of the social context through the music as a possibly significant direction for Javanese musicology if a richer, less purely structuralist analytic discourse is to be achieved.

Sumarsam is at pains to probe behind the construction of the persistent adi luhung high-art image for Javanese gamelan in his Chapter 3, "The Impact of Western Thought on Javanese Music." In other words he seeks to peel back the layers of aesthetic agendas invented for gamelan by its various constituencies during the past one hundred fifty years, culminating in the collaborative theory discourse of recent

17 A. Vickers, The Desiring Prince: A Study of the Kidung Malat as Text, (PhD Dissertation, University of Sydney), p. 149.

${ }^{18}$ M. Bandem, and F. DeBoer, From Kaja To Kelod: Balinese Dance in Transition, (Kuala Lumpur: Oxford Press, 1981), pp. 97-101. 
decades. He casts a broad net and touches at least briefly on the contributions of a long series of events and personages. The material here is familiar, for the debates about notation, nationalism, and the role of the academies in developing terms and theories have been visited and thematized by others ${ }^{19}$. From a disciplinary perspective this is good because ethnomusicological studies are too mutually isolated. On the other hand there is also a certain (perhaps inevitable) restraint in Sumarsam's writing of this history because he is so deeply implicated, and not inclined to deal with his predecessors harshly. Compare, for example, the most critical thing he says about Kunst-"To what extent Kunst based his findings on the opinions of the musicians is not clear." (146)-with Judith Becker's less forgiving reappraisal, written on the occasion of a reissue of De Toonkunst von Java. ${ }^{20}$

In the final chapter, "Current Theories of Gendhing," Sumarsam at last brings his skills as a performer directly to bear in order to present his most recent insights into musical structure. He does not accomplish this without injecting a note of discontinuity, however, for in this chapter the bird's-eye view is abruptly jettisoned in favor of the magnifying glass. The analyses of gendhing given here do not emerge from a systematic application of the historical insights of the foregoing chapters as a methodological framework, as one might hope (much as one might hope that a paradigmatic ethnomusicological study in the anthropological mold would use extensive cultural information to show the relevance of context and social function to musical structure). Rather we are given a chapter-length illustration of the current situation as Sumarsam defined it at the end of Chapter 3, and it is at this juncture that the autobiographical subtext of the entire work is most fully revealed. Sumarsam the storyteller suddenly becomes protagonist, a master gamelan player laying down his mallet and walking to the front of the pendhopo to deliver a learned disquisition about the richest and most aesthetically satisfying ways to perceive the standard repertoire. The audience, made up of other performers, is rapt, for they know all the pieces, care deeply about them, and have discussed them themselves before.

If one is prepared to accept this change in tone and perspective, the rewards are substantial because Sumarsam is bolder here than elsewhere in the book. He is prepared to engage directly those who have promulgated the notion that gamelan composition is primarily or exclusively formulaic; that is, based on the shuffling of a limited number of melodic contours and rhythmic groupings, and to do it in a much more worldly way than he did when he put forth the notion of inner melody. That emerged from the ruminations of a musician pondering his stock of performing resources at close range, whereas the current chapter comprises a more sweeping reassessment.

The tidy scientific approach to analysis he challenges herein was that taken in turn by Hood, Becker, and Sutton, among the foremost Western writers of the past several decades; each in his or her own way in the thrall of imperatives in ethnomusicology and driven to reduce the music to its most $u r$ form $^{21}$. That their tactics led to oversimplifications might not have occurred to them at the time, for ethnomusicology

${ }^{19}$ However only Perlman, Music Theory, gives comparable detail.

${ }^{20} \mathrm{~J}$. Becker, "Review of Jaap Kunst's 'Music in Java,'“ Ethnomusicology XIX, 2 (1975): 310-15.

21 I am referring to Hood, Nuclear Theme; Becker, Traditional Music; and Sutton, Variation. 
had in part been seeking its identity in other music disciplines, and Western music theorists were busy performing such reductions on their chosen repertoires. Hood felt compelled to legitimize gamelan as an area of research in the first place, and therefore endeavored to point out how cadential formulae and melodic relationships in gamelan gatra (four-note successions in the balungan) were subject to the same kinds of rigorous interrelations of inversion, transposition and so on, as the music of Western contrapuntalists like J. S. Bach. Becker turned to Chomskian generative grammars to explain gendhing in terms of an astonishingly small and comprehensible collection of melody bytes and their transformations. Sutton borrowed from Lord and Bateson to depict gamelan via the "network of interconnection between pieces" that exists in oral tradition ". . . not only in the general formal premises that underlie them but in the actual melodic content of each one ... these formulas, used again and again from one piece to another, unite the tradition into a coherent whole."22

Becker was prescient enough to include a caveat that any student of Mozart would approve of, namely, that formulaity is not the exclusive provenance of oral tradition musics. ${ }^{23}$ It is of course easier to ask this in our contemporary milieu, where the notion of systematic cultural coherence is itself under siege, but what engaged gamelan musician could be satisfied for long with the reductive idea that gamelan structure is reducible to combinatorial strings? Sumarsam's strategy is not so much to discredit formulaity as it is to redefine it merely as a perspective while simultaneously offering abundant and convincing evidence that gendhing also arise from sekar, the vocal/text traditions with more than a millennium of history on Javanese soil. The flexibility of sekar is the perfect foil for the rhythmic fixity of gongan and gatra. Thus Sumarsam is able to assimilate the published theories and at the same time strengthen for posterity this obvious yet somehow underinvestigated notion, that Javanese instrumental music should have grown from song. Appropriately, he does not claim that this is the sole source, but

the evidence presented ... shows that the compositional process in gamelan music cannot be explained in one particular way (e.g. the creative act of manipulating gatra). Composing melodies is a complex process consisting of (1) reformulation of vocal melodies, (2) creative use of existing melodic material (the result and the expansion of process [1]), and (3) consideration of instrumental elements. In other words, the bulk of the gendhing have heterogenous and even syncretic origins. (229)

In a different way, McPhee considered but was barely able to imagine reaching for the same conclusions about Balinese music in the 1930s. Below, when he writes of "freely conceived melody" in the compositions of the court gong gde gamelan, he is also hinting at an origin in song:

There will always be the question of whether the pokok tones are true nuclear tones which serve for full melodic realization, or whether, after all, they are no more than emphasis tones to a more freely conceived melody. In the shorter and more

\footnotetext{
22 Sutton, Variation, pp. 44-5. The Lord work is the classic The Singer of Tales (Cambridge: Harvard University Press, 1960), and the Bateson is "Bali: The Value System of a Steady State" in Traditional Balinese Culture, ed. Jane Belo (New York: Columbia University Press, 1970), pp. 384-401.

${ }^{23}$ Becker, Traditional Music, p. 144.
} 
lyrical gending gangsaran that could well be the case ... But in the finely balanced proportions of the gending ageng and the planned arrangements of the nuclear tones, the . . . melody is clearly subordinate to what seems to be an intellectually conceived composition. ${ }^{24}$

In researching the archaic Balinese gamelan gambang, McPhee had hopes that he could reconstruct a link to sekar madya poetry, but was unable to gather convincing evidence. During his near-decade in Bali, McPhee was more than busy studying instrumental traditions, and he bypassed the study of vocal music almost entirely. As a result he was unable to do more than speculate. Later work on Balinese vocal traditions helped establish a more concrete connection than McPhee was able to, but to the present this has still not been well-demonstrated for Bali. ${ }^{25}$ Indeed, there is usually insufficient time in the field for any outsider to learn to represent the music with appropriate multidimensionality. In this regard Sumarsam has played a trump card when he calls upon his Javaneseness to guide this study. Clearly as his appreciation for the collaborative atmosphere in gamelan studies comes through, we are still willing to grant in the end that a Westerner has not yet-and perhaps for some time will notbring us as close to the heart of the matter as he has.

This book is both the story of Sumarsam's lineage and a defense of his purposes, a personal intellectual history in which he acts as both dalang and wayang puppet. As an emblem of the contemporary international status of Javanese gamelan, Sumarsam himself is one of the most conspicuous upholders of both its practice and the adi luhung perspective on it. With his depiction of culture and musical structure as dynamically syncretic, central Javanese gamelan, fragmented through the specialized perspectives of recent research, has been put together again.

\section{Interactive Mode}

If Sumarsam's book provides holism within the narrow scope of historical and analytical studies about Javanese gamelan, Brinner's aspires to a broader holism by posing abstract questions about learning and performing music as a human behavior and answering them in numerous contexts. Conceptually, at least, gamelan is only one of these, although the book is anchored by pervasive reliance on Javanese examples. Displaying an ethnomusicologist's characteristic love of interdisciplinary approaches coupled with a welcome new emphasis on cross-cultural comparison, the focus is not on Javanese music per se, and the intended audience is not the Javanist community per se. Instead gamelan is employed as a reference point in the construction of models for how musicians in Java and elsewhere develop and use their skills. Six of the eleven chapters are primarily devoted to these models, while the remainder test them in Javanese musical situations. Brinner's central concern is musicians' experience: how they learn, what they are expected to know, how they critique themselves and one another, their means and ends for mutual communication during ensemble perfor-

24 C. McPhee, Music in Bali (New Haven: Yale University Press, 1966), p. 96.

${ }^{25}$ See Ernst Schlager, Rituelle Siebenton Musik auf Bali (Forum Ethnomusicology I: Basle Studies in Ethnomusicology, 1976) and Richard Wallis, The Voice as a Mode of Cultural Expression in Bali (PhD Dissertation: University of Michigan, 1980), and A. Vickers, "Kidung Meters and the Interpretation of the Malat" in Balinese Music in Context, D. Schaareman, ed. (Forum Ethnomusicology IV: Basle Studies in Ethnomusicology, 1992). 
mance, and the social and musical structures and conventions within which they do so. The introduction aptly asserts his purposes and the undeniable appeal of his subject: " ... .we are bringing the musician to the fore, within the relevant social and cultural contexts. That in itself is a worthy goal ..." (5)

The concerns are explored via three levels of inquiry, ranging from general to specific to comparative in scope: first, the identification of categories and themes descriptive of musical competence and interaction in the abstract; second, their detailed application to the local and particular issues faced by Javanese musicians and ensembles mastering their art; and third, their comparative application to a broad selection of world musical contexts. The book moves adroitly among these areas and as a result has a sustained character of exuberance. Since Java is the exclusive concern of the second level and examples from Java and Bali surface regularly in the third, these aspects of the book may be most relevant for the current article and will be my principal concern below. First I will turn to the most general level.

The general observations are presented for the sake of theoretical elegance. Consequently they stem less from close musical details and more from the perceived need for top-down application of organizing principles. The range of conceptual categories broached and explored is thorough, for Brinner is shaping a full-fledged alternative theory of music that aims for universal applicability. All of the conventional categories of analysis in ethnomusicology (Merriam's "concept, behavior and sound" are the operative summation) are reformulated to foreground performing musicians' concerns and dispositions. He is also appropriately sensitive to the hazards of over theorizing, as in the exemplary Chapter 7, "Toward a Theory of Musical Interaction":

To comprehend such a variety of interactions, we need a theoretical structure that is rich enough to capture the detail and mirror the complexity of interaction in specific musical contexts without losing a level of abstraction sufficient for comparison. (169)

There are times when Brinner does not heed his own advice well enough, especially when borrowing concepts from disparate academic fields. Of course, such appropriation is neither a priori good nor bad; it is all a matter of whether the material under discussion calls for an interdisciplinary clarification. Among others, Brinner appeals to artificial intelligence research in Chapter 1 and to sociology in Chapter 10. In the former, "Modeling Musical Competence," he draws on existing studies of cognition and knowledge modeling to describe kinds of musical apprehension and awareness. Dichotomies and discrete epistemological domains (passive/declarative, explicit/intuitive, and so on (34)) are asserted, interlinked, and mapped. Certain types of statements with both a musical and cognitive science referent are thus enabled: for example, that gong players may have only passive knowledge of patterns that drummers have actively mastered; or that music teachers may be in the position of having to devise explicit explanations of musical practices that performers need only apply intuitively. One should first of all praise Brinner for enriching and codifying, in a time-honored scholarly fashion, a domain of musical knowledge and experience heretofore rarely examined through this particular lens. One can also argue that by retrofitting musical knowledge in AI garb he is reinventing the wheel and may have been able to dispense with some of the extra conceptual baggage, allowing the terminology to speak for itself in a purely musical context. Although the book's own 
self-justification may ultimately rest on the architechtonics that this interdisciplinarity provides, I view it as something of a necessary evil in this particular case. In theorizing about individual musical behavior Brinner accepted the risk, perhaps higher than in other music scholarship, of over-formalizing aesthetic attitudes. This may enable access to certain intellectual perspectives, but the danger is that it creates a frame of symbolic abstraction that threatens to de-aestheticize the subject, in the same way that music notation separates a performer from musical sound even as it helps to create it. Later, in Chapter 10, "Individuals Making Music Together," Brinner enters congruent terrain via application of borrowed concepts such as framing, staging, and facticity. (288-9) One need not invoke sociologist Harold Garfinkel's formulation of the latterglossed here as a state of intersubjective reality - to say that musicians live and work in such worlds.

This is not to say that the book is unsuccessful as a whole in balancing theory and data, simply that it does so more effectively in some places than others. The examples from Chapters 1 and 10 cited above succeed less fully than those in Chapter 7. Here Brinner's four organizing parameters (interactive network, interactive system, interactive sound structure, and interactive motivation (169)) work swimmingly because one senses that the concepts have emerged organically from the Javanese data to which they are later applied rather than having been borrowed and made over for the occasion. The first three parameters refer to what any performer would recognize as fundamental domains: network to the roles assigned to different players or instruments in an ensemble, system to their orientation and means for sending musical communications to one another in performance, and sound structure for the umbrella of conventions that organize the disposition of sound in musical space-time and provide a normalized framework for music-making. Motivation grapples with the human dimension: the personal, social, or cultural reasons for musical behavior. In this last category an effective critique of essentializing "cultural" explanations for musical behavior is generated. How, it is asked, can one effectively posit simple correspondence, as more than a few writers have done, between Balinese and Javanese gamelan and their societies' respective cultural ideals by referring primarily to insufficiently nuanced terms like gotong royong? (202)

In turning to the Javanese music components of the book we are presented with a range of authoritative information. Some of what Brinner writes about local gamelan issues comprises sets of elemental facts and musical maneuvers seen from the standpoint of an experienced performer, but the many eloquent formalizations and descriptions are new and useful. Gamelan musicians may come to the book in part to see these fundamentals mindfully inscribed, and they should enjoy the pleasant shock of recognizing their own learning experiences and intuitive musical behaviors while reading it. This is especially true in the many passages where comparisons of Javanese and Western players learning gamelan are used illustratively. Issues of less immediate concern to performers but thematized in earlier scholarship arise as well, and usually in new ways. The introduction of kepatihan notation, for example, was treated by Becker as a technological innovation leading to changes in the way music is perceived and discussed. ${ }^{26}$ Here it is viewed with less circumspection right alongside older ways of encoding musical knowledge such as drum mnemonics and solfege, all under the

26 Becker, Traditional Music, p. 11. 
rubric of symbolic representations (49) and the manner in which they alter or enrich competence. The beneficial effect is to emphasize notation's continuity with other ways of knowing instead of its discontinuity with oral practice.

Familiar approaches to music theory subjects are enlivened through de-abstraction and attention to what the performer needs to know. Writings by Kunst, Hood, and Becker that helped elevate the subject of pathet to the status of music theory locus classicus are depicted as flawed because of their naive assumption that pathet is a reified theoretical construct wholly inherent in the balungan. Labeling such perceptions as declarative knowledge of only partial utility, Brinner notes, as other recent writers have, how complementary procedural skills are what bring the balungan to life. He also explains how the "illogical" classification schemes in use serve an important function by providing a comprehensible "prototype" for knowledge classification that musicians comfortably disregard whenever the situation requires it. ${ }^{27}$ (61-3) Rather than attempt to "pin down" pathet, its diffuse representations in practice are explained in terms of intuitive knowledge acquired through oral learning processes. (145-46) These may be only distantly related to the less flexible musicological representations. The perspective of seeing pathet mastery as an aspect of musical competence provides a more multidimensional context for understanding it. Moreover, noting that "the relatively broad Javanese tolerances of fidelity in imitation are also due to the general lack of extensive and specific feedback from a teacher or other more knowledgeable musician" (135) ties the proliferation of variants to weak links in the chain of transmission with engaging irony.

Chapters 8 and 9 ("Interaction in Javanese Gamelan" and "Interaction in Javanese Multimedia Productions") present the most detailed musical analyses, applying the parameters of Chapter 7 to performance procedures in cyclic gendhing, palaran, pathetan, and several wayang genres. Throughout, cleverly designed flow charts illustrate performer cues and response choices and capture the kinetic complexity of performance perhaps even better than a conventional musical score can, though of course with a different kind of precision (we await the CD-ROM). In more noteoriented musical examples the pervasive use of kepatihan notation (only one example is given in Western staff here, plus one in an earlier chapter) is regrettable in that this book is pitched to a less specialized readership than Sumarsam's. Though efficient for a number of editorial reasons, it places a severe obstacle between the uninitiated reader and the heart of the matter. Yet the apt marriage of methodology and subject is striking throughout, for the complex of interactive possibilities in Javanese gamelan is vast yet uniquely constrained by the sound structure and hence susceptible to vivid description in the particular formats adopted. A similar intensive focus on Balinese gamelan or the Western orchestra would yield less because fewer structurally significant choices are relegated to performers, while in jazz and Indian music the comparatively unrestricted

27 Perlman, Music Theory, especially pp. 399-460, provides many specific instances and goes far deeper in explaining how these epistemological dissonances are actually resolved, all the while hewing much closer to an ethnotheory perspective in which Javanese terms and concepts are used with as little distortion as possible. Brinner's encapsulations have great explanatory value, but they are meant to be more general and applicable cross-culturally. Taken together, Perlman's comprise an authoritative primer of Javanese gamelan performance skills. In a case such as "prototypes," Brinner is interested in the cognitive apparatus that tolerates them despite the limited accuracy of their representation; Perlman seeks to discover their specific shortcomings. 
scope of improvisation would require an entirely different approach, presumably more resistant to formalization. This becomes clear enough even without leaving the island of Java: we learn that experimental STSI genres like Wayang Padhat are so prearranged that they "drastically alter the network and sound structures of the Central Javanese tradition and affect the interactive system, too, pushing it beyond its capacity for spontaneous expression." (284) Is it then fair to say in such cases that the model is no longer useful? It may be illusory to suppose that the model of interaction proposed in this book is universally applicable, as Brinner hopes it to be; rather it uniquely fits the primary repertoire to which it is applied. Due to its genesis in the particular ecology of structure and spontaneity in Javanese gamelan, the model's applicability to other music may depend on how compatible that music is with Javanese.

The model can nonetheless lead to penetrating observations about other kinds of music, so long as these are understood to be more ad hoc and to have Javanese music as their (implicit or explicit) final frame of reference. Indeed, the book takes meaningful steps toward addressing the second problematic area for Indonesian musicology that I identified earlier in this essay, and is ultimately best appreciated as a contribution to the dormant comparative discourse in ethnomusicology. This is an insightful venture that demonstrates how, with the right combination of imagination and perception, musical traditions from around the globe can be coaxed into exhibiting their commonalties.

Indonesianists ought to welcome this perspective for the way it deisolates and demystifies gamelan, freeing it from whatever scholarly constraints are suggested by its particular local context and enmeshing it in the kind of dialogue it is equally suited for in this day and age: one in which it is engaged on equal terms with other remarkable musical systems of the world. It is not that there is any lack of cultural sensitivity in these pages; nor is there anything less than a full grasp of the value of the differences between central Javanese gamelan and all other music. It is more that Brinner's conceptual framework allows local musical knowledge to bypass interpretations which render it comprehensible exclusively in terms of the way Javanese and Balinese culture have been constructed and leap directly to an international field. The paradigm of cultural uniqueness has begun to shift, and this is a fine attempt to locate test sites for discussing music in terms other than culturally bounded ones.

Under the subtopic of "interactive network," the gamelan is compared with the symphony orchestra to depict the range of leadership, support, and accompanimental roles musicians take. Under "system and sound structure," examples from West Africa and across Asia are used to show the functional equivalence of time line, tala, and colotomic patterning. On page 206 alone we are refreshed by discussion of the contemporary Polish composer Lutoslawski, South Indian Bharatnatyam accompaniment, and Balinese dance music in close succession, under the rubric of the various motivations that impel musicians to stretch for a sense of excitement in their performances. Marvelous analogies between seemingly unrelated musical behaviors open up new avenues of thought. One of the most memorable links Balinese kotekan (interlocking parts) with Western functional harmony from an interactive perspective, noting that "in both cases the two or more players are striving to create a composite and must match envelope (attack, sustain, release) and often timbre, too, in order to blend; but 
one relationship requires orientation to a composite simultaneity (a chord) and the other to a composite that unfolds consecutively in time." (178). Wonderment about the variety of social and musical constraints that give rise to group musical situations around the world shines in passages such as these. It is gratifying to read, at the outset of the chapter, that the initial impetus for the entire project stemmed from this enduring admiration. The need to make sense of this variety is akin to American composer Henry Cowell's celebrated assertion of wanting to "live the whole world of music," and the peculiarly Western mirror image of Sumarsam's desire to look deep into his own culture.

When will a Javanese or Balinese author a book about Western music, or one about gamelan that benefits from a bi-musical perspective on the West (or elsewhere)? I ask this in part rhetorically, having raised the issue earlier as a problem, but also because in conclusion it seems appropriate to propose a next step. I do not wish to impose Western music on gamelan musicians, but neither can I conceal high hopes for what such an individual might contribute. ${ }^{28}$ Thus far there is precious little evidence of Indonesian interest in Western art music. The few isolated cases of Indonesian conductors or pianists achieving international success are insignificant compared to the flood of formidable Chinese and East Asian performers and composers crowding North American concert stages and conservatory corridors. ${ }^{29}$ In many Asian nations Western music plays an appreciable role, always in varying degrees of assimilation and in accordance with the host country's own situation. ${ }^{30}$ But in Southeast Asia and India (with the possible exceptions of Malaysia and Singapore) its impact is considerably smaller, for reasons which also vary.

There are obvious explanations for why ignorance of or indifference to Western music outside the mainstream of popular culture remains strong in Indonesia. Perhaps, as was suggested, fear of cultural domination persists. Western music has higher international prestige than gamelan, and its inclusion might be thought of as deleterious to the health of Indonesian "classical" music. It is unlikely that many people stop to think about this, however, and there are other, more specific reasons. Sumarsam discusses Dutch-provided waltzes and military fanfares as a part of kraton ceremonial life in the nineteenth century (74-76), but little assimilation occurred, and the impact of this practice today is only to be found in peripheral genres like tanjidor brass bands. In current Indonesia the capitol of Western cultural influence is also the national capitol, while gamelan activity is rooted elsewhere. The sporadic presence of a symphony orchestra in Jakarta and outspoken Western-trained musicians like Franki Raden and Slamet Syukur intersects hardly at all with the life of karawitan in Yogya and Solo. Experimental composers from STSI and other arts academies trained in

\footnotetext{
28 See Marc Benamou, Approaching and Hanging: Metrical and Melodic Organization in Javanese and Western Music, (MA Thesis: University of Michigan, Ann Arbor, 1989) for an example penned by a Westerner.

29 Of the few Indonesians internationally successful in Western music (such as the conductor Jahja Ling) none to my knowledge have gamelan backgrounds in any case.

${ }^{30}$ See H. Ryker, "Introdution" in New Music in the Orient, H. Ryker, ed. (Buren: Frits Knuf Publishers, 1990) for a summary of the concerns and challenges facing Asian composers of Western art music.
} 
Indonesian musical traditions have been welcomed internationally by gamelaninclined Western composers, performers and audiences as brethren, without any indication that mutual understanding of each other's native musical tongues is called for or even necessarily desirable. And needless to say, outside of artistic communities the common Indonesian conception of Western music is a conflation of the simple and basic tonal song structures learned in public school (derivative of church hymns or military music) with mass-market pop music. This is unsurprising, and perhaps not too different from the situation in the West itself, but hardly a conducive mixture as far as the desire and ability to comprehend high-art genres is concerned.

If this one-way street is the zeitgeist of so-called cross-cultural interaction, one can hardly expect that it would be otherwise for scholarship. The impetus for a change in the situation will probably have to come from a combination of encouragement from Western scholars and extraordinary motivation on the part of Indonesian ones. Sumarsam's unique position in the community of gamelan experts makes this seem a remote albeit conceivable development. Brinner holds out the promise of what can be achieved when music is allowed respite from the quarantine of culture. As both books illustrate, there is no shortage of horizons for Indonesian musicology to aspire to, even when the discussion remains anchored in the core traditions of central Javanese gamelan music. But for as long as these boundaries are as clearly etched as they have been, there will be a great deal that remains unexplored. 